\title{
Parking versus Congestion Pricing: Comparative Analysis
}

\author{
Draženko Glavića, Jelena Simićevića, Marina Milenkovića \\ a University of Belgrade, Faculty of Traffic \& Transport Engineering
}

\begin{tabular}{l} 
A R T I C L E I N F O \\
\hline DOI: 10.31075/PIS.66.03.02 \\
Professional paper \\
Received: 05.04.2020 \\
Accepted: 01.09.2020 \\
Corresponding author: \\
marina.milenkovic@sf.bg.ac.rs \\
\hline Keywords: \\
Congestion Pricing \\
Parking Charging \\
SWOT analysis \\
Transport Demand Management \\
\hline
\end{tabular}

\begin{abstract}
A B S T R A C T
This paper through comparative analysis of parking charge and congestion pricing features, aims to highlight their possibilities and identify limitations, and thus to encourage transport policy makers to implement them. Both policies can tackle with negative consequences of traffic, such as pollution, noise, accidents, etc. But they still differ in a way they act on car users. Analysis of this similarities and differences will be main task of this paper. The results of analysis can be useful for better understanding of effects of both policies when selecting measures that can be used by decision makers in solving congestion in cities.
\end{abstract}

\section{Introduction ${ }^{1}$}

Due to a constant increase in traffic volume, large cities face with traffic and parking congestion problems. Congestion causes numerous negative consequences such as: air pollution, noise, space occupation, illegal parking, delays, fuel waste, traffic accidents as well as the stress of all road users. Expanding road and parking capacity is often impossible in city centres and usually is counter-effective, as building more roads and parking spaces induces additional demand. The only long term, sustainable, solution in central city areas is transport demand management (TDM). Rather to capacity expansion, TDM is based on the change of travel behaviour, and thus on modal, spatial and temporal redistribution of transport demand, resulting in more efficient use of existing transport resources. It insists on the reduction of car usage, in favour of alternative transport modes.

TDM typically implies the application of set of measures selected based on and adjusted to local conditions and management goals. Such set normally combines restrictive (push) measures which discourage driving and positive initiatives for accepting more sustainable behaviour (pull measures). Application of push and pull measures leads to better results due to their synergistic effect.
Additionally, pull measures contribute to better acceptance of push measures. In this paper we focus on two acknowledged push TDM measures: Parking Charge (PC) and Congestion Pricing (CP).

PC means direct charge to drivers for using a parking space, depending on their duration of stay. On the other hand, CP means charging to drivers for entering into the central city zone CP by using user friendly technologies that do not require a change in speed or stopping, (Glavić et al., 2017a; Glavić et al., 2017b; Milenković et al., 2018). Both transport charges present direct costs to drivers, to which they are particularly sensitive, hence some drivers change their behaviour in order to reduce travel costs. Driver responses may include changes in transport mode, parking location, routes, travel frequency and so on.

Since PC and CP charges different services and in different ways, they can affect different demand segments and provoke different responses. CP primarily affects through traffic to change routes which do not pass through the city center, but can also affect origin-destination trips.

On the other hand, PC is concentrated on the origindestination trips (i.e. parking demand) whereby it affects long-term parkers more. 
PC is traditionally applied to reduce parking demand and thus to solve or mitigate parking problems in highly attractive areas such as city centres. Furthermore, considering its wide mechanism of action on travel behaviour, PC is also used to reduce traffic volume (Litman, 2010) through reduction in number of cars in city centres as well as reduction in parking search related traffic.

While CP is considered the most effective policy for addressing traffic congestion, $P C$ is often referred to as the second best one (Albert and Mahalel, 2006; Kelly and Clinch, 2006). Nevertheless, PC is much more commonly in use because it is relatively easy to apply and is better accepted by users in comparison to other restrictive measures (Marsden, 2006; Verhoef et al., 1995). It can be said that PC has been implemented in most cities worldwide, while the application of CP is sporadic so far. Although parking is charged in most cities, it is generally believed that parking is under-priced, hence full effects of this policy are missing. This is also the reason why in this paper PC will actually refer to parking price management.

In addition to the above explained benefits, it should not be neglected that both policies generate revenue, which can be further invested in transport system improvements. On the other hand, transport charges are sometimes criticized to be unfair as they affect low income users more. Many authors disagree with that, explaining that unless an individual driver pays for the damage he/she causes to the society when participating in traffic congestion and/or occupying $20 \mathrm{~m}^{2}$ of expensive parking area, the burden of costs will fall to the society, and that is unfair. Finally, it is confirmed that there are gender differences in the response to and acceptance of transport charges, whereas females are more sensitive to them (see e.g. Polk, 2003; Polk, 2004). This is an important issue for achieving socially sustainable transport system.

This paper aims, through comparative analysis of parking charge and congestion pricing features, to highlight their possibilities and identify limitations, and thus to encourage transport policy makers to implement them. It should also provide them with general assessment of what policy could be more appropriate for local circumstances and management goals.

The structure of the paper is as follows: Section 2 provides literature review on PC and CP. Section 3 shows a comparative analysis of these two policies. Section 4 summarises the concluding considerations.

\section{Literature review}

Considering the importance of these policies in addressing transport problems, many researchers have been investigating the impacts of parking charge (Section 2.1) and congestion pricing (Section 2.2) on travel behaviour, and further on transport demand.
However, studies that compare impacts of these two policies are rare. Exceptions include the research of Shiftan and Golani (2005). Results from the central area of Tel Aviv (Israel) show that most likely response to PC and $\mathrm{CP}$ is modal shift, while change of trip destination and trip cancelation are unlikely to happen; which is a positive finding for sustainable development.

In addition, Albert and Mahalel (2006) compared driver attitudes towards parking and congestion prices and explored their effect on travel behaviour. Results show that drivers are very sensitive to parking price increase and congestion pricing introduction, hence they are willing to change their behaviour in order to avoid additional travel costs. Still, drivers would rather pay for parking (elasticities amount -1.2 vs. -1.8 ), consequently congestion pricing would be more efficient in reducing transport demand.

\section{1. $P C$ literature review}

Parking charge is acknowledged policy for managing parking and transport demand. Analysis of the current studies shows that drivers are sensitive to PC introduction and price increase, whereas price elasticity of demand is usually in the range from -0.1 to -0.6 (TCRP, 2005). With this regards, PC introduction and price increase directly impact traffic with origin/destination in the subject area, i.e. parking demand. Numerous studies confirmed this conclusion. Below are some of them.

Van der Waerden et al. (2006) examined changes in travel behaviour as a response to planned parking measures at the Eindhoven University of Technology (Netherlands) campus. It is shown that almost a half of drivers would change their behaviour if they had to pay entry into the campus by changing the transport mode or by parking outside the campus.

In 2011 San Francisco Municipal Transportation Authority launched SFpark project at around 7,000 parking spaces with the aim to achieve targeted parking occupancy by defining spatially-varied parking prices. The procedure for defining parking price was as follows: parking prices were initially set; based on data gathered by parking sensors, parking occupancy was monitored on block-by-block basis and prices were adjusted in response to the occupancy rates once every six weeks.

Pierce and Shoup (2013) used data from price and occupancy changes during the first year of the project implementation, in order to analyse user sensitivity to price change. An average elasticity amount -0.4 , but it significantly varies in relation to many parameters, such as: "location, time of day, day of the week, initial price, and date of the price change". 
Simićević et al. (2013) used data from Belgrade (Serbia) to examine the impact of parking price and time limitation on transport/parking demand. The most common response to price increase would be a modal shift. A negligible number of users would give up the arrival to the area. This is an important result considering the concern that restrictive parking measures can jeopardize area's attractiveness and economic efficiency.

Due to reduction in parking occupancy rates, a vacant parking space is easier to find, therefore parking search related traffic also reduces, resulting in decreased traffic volume. Simićević at al. (2018) used data from the central area of Belgrade (Serbia) to investigate the impact of parking measures on parking search time. They concluded that price increase leads to decreases in parking search time and therefore in $\mathrm{CO}_{2}$ and $\mathrm{NOx}$ emissions. Just by equalizing the on- and off-street parking prices, the average search time would decrease by $32 \%$, and $\mathrm{CO}_{2}$ and $\mathrm{NOx}$ emissions by $14.1 \%$ and $14.2 \%$ respectively.

The belief that parking policies do not impact through traffic is widely accepted (Saleh and Sammer, 2009). However, some researchers claim that better conditions on the road network (due to reduced origin/destination car traffic and parking search related traffic) can increase volume of through traffic (see e.g. Shiftan and BurdEden, 2001).

Lately, on the basis of numerous researches which examine parking price impact on car usage and congestion, it has been established that there is the individual impact which must be examined and included. With this regards, below is a brief review of the studies dealing with this topic.

Kelly and Clinch (2006), based on data collected at onstreet parking spaces in the central area of Dublin (Ireland), examined differences in responses to parking price of users with purpose "business" and others. It is shown that, while at the lower price levels there are no significant differences in responses of these two demand segments, as parking price increases this difference progressively increases. This means that there is a price threshold where different demand segments start to behave differently.

Using stated preference data, Simićević et al. (2013) found that users with purpose "work" are more sensitive to parking price increase than others. This finding was expected considering heavy travel frequency and long parking duration of these users. Such behaviour pattern is very promising, since these drivers are undesirable in city central areas, since they travel during peak hours and occupy parking spaces for a long period of time.

Khodai et al. (2010) estimated behaviour of users hypothetically faced with the different parking prices in the Tehran central area (Iran). Paper objective was to determine parameters which impact user behaviour, and the aim to define critical level of parking price (the price at which users would avoid parking in the area). It was concluded that travel time and monthly income are most influential parameters for car use. Price increase by 4,000 IRR (0.25 EUR) per hour would encourage $99 \%$ of users to give up driving.

Simićević and Milosavljević (2016), on the basis of the study before and after $50 \%$ price increase at public parking garages in Belgrade central area (Serbia), concluded that (in line with expectations) heavy parkers are more sensitive than those who park occasionally. Earlier results based on stated preference data (Simićević et al., 2013) data were confirmed: commuters are the most sensitive to price increase. In addition, it was found that older drivers are more affected by price increase then the younger ones, which can be explained by their lower income. This finding is negative in the light of contemporary tendencies to encourage the mobility of elderly.

In contrast, Hess (2001) concluded that younger population can be more easily influenced by parking measures. This is explained by the greater willingness of young people to try something new. Contradictory findings point to the conclusion that user behaviour is highly influenced by local factors, therefore the results cannot be copied from another city but rather investigated for each particular case.

\subsection{CP literature review}

Schade and Schlag (2003) analysed acceptability of road pricing strategies in four European cities: Athens (Greece), Como (Italy), Dresden (Germany) and Oslo (Norway). The findings show that the acceptability of the investigated pricing strategies is low and that variables referring to social norms, personal outcome expectations, and the perceived effectiveness are positively related with the acceptability of pricing strategies.

Jaensirisak et al. (2005) conducted a survey in order to determine the differences between car-users and noncar users, to determine the effects of scheme design and to determine level of charge on CP. Data collection was conducted in two UK cities. Charging was found to be more acceptable to non-car users, those who perceived pollution and congestion to be very serious, those who considered current conditions unacceptable, and those who judged road pricing to be effective.

Eliasson and Jonsson (2011) analysed how car dependence, transit satisfaction, education, residential location relative to the toll cordon and attitudes to environmental issues influenced the attitudes to the $\mathrm{CP}$ after the CP had been introduced in Stockholm. They found a strong connection between environmental concerns and positive attitudes to $\mathrm{CP}$. 
Liu and Zheng (2013) examined the public acceptance of $\mathrm{CP}$ in Brisbane (Australia). It was determined that female drivers had a more positive attitude towards CP than males, also public transport users were more supportive than car drivers. Those who drove to the city center when travelling to work were concerned about the attractiveness of working in the city center. Drivers were skeptical about CP because they thought that the existing public transport system capacity was not sufficient for increasing the demand after the implementation of CP. It was shown that respondents with higher income would less likely give up on driving or would travel rarely in the city centre.

Dieplinger and Fürst (2014) tested the acceptability of certain pricing strategies among car drivers and factors which had an impact on the level of acceptability in five European cities - Vienna, Athens, Como, Dresden and Oslo. The obtained results show that acceptability in Vienna is significantly higher than in all other cities due to: 1) clearly defined CP purposes in Vienna - the way in which the collected income will be spent; 2) price in Vienna depended on the distance driven whereas in other cities users were supposed to pay a fixed amount when entering the toll area; and 3) users awareness of both $\mathrm{CP}$ necessity and usefulness in Vienna.

Grisolia et al. (2015) analysed which factors should be considered to increase acceptability in the case of the Spanish city of Las Palmas de Gran Canaria. The results of the analysis show prior resistance to any charging system, a lack of confidence in politicians, and the importance given to the use of revenues. Values obtained from the experiment suggest that public acceptability relies on the characteristics of the CP scheme. In particular, more than one third of the population would be willing to pay a daily fare of $€ 2.22$ if revenues from the system were used to increase the size of green areas instead of reinvesting this into the transport system.

Nilsson et al. (2016) dealt with Gothenburg residents' attitudes towards CP. They conducted surveys, before the implementation and after. Information about the system did not have an influence on the support, but it was important for understanding. The influential variable for the support was experience. The respondents were more supportive if they believed that the system had positive effects on the environment, even if there were some negative effects on their personal situation.

Eliasson (2016) discussed and analysed whether CP could be considered to be "fair. Two different perspectives were distinguished: the consumer perspective and the citizen perspective. Surveys were conducted in four European cities: Stockholm and Gothenburg (Sweden), Helsinki (Finland) and Lyon (France). The results show that it is hard to find much support of the view that CP is unfair, as long as its purpose is to correct prices and allocate scarce resources. Both in terms of absolute payments and compound self-interest, lower income groups fare better than average. From a citizen perspective, differences are small, but lower income groups fare at least as well than high-income groups.

Hess \& Börjesson (2017) tried to understand Stockholm, Lyon, Helsinki and Gothenburg residents' attitudes about $\mathrm{CP}$ after conducting surveys in these cities. In all cities a random sample of adult residents was recruited to participate in the survey. They showed that attitudes about environment, equity, pricing and taxes had a significant influence on supporting and creating attitudes towards CP. Respondents with higher income gave support to $\mathrm{CP}$ and were less worried about equity, and respondents with more cars were less worried about the effects on the environment. Attitudes depended on education and gender. Experience with a similar system had a significant influence on the congestion pricing support.

Milenković et al. (2018) examine users' attitudes on the introduction of congestion pricing in Belgrade (Serbia). Users' attitudes were collected by conducting a poll of questions related to the socio-demographic characteristics of users, O-D matrix of car drivers, and questions regarding the policy of congestion pricing. The obtained results show that respondents recognized the problem of congestion pricing in Belgrade central zone and that they would support this strategy.

Farrell and Saleh (2005) analysed the allocation of revenue from a CP from the aspect of car users, public transport users and cyclists and walkers in the city of Edinburgh. They found that the revenue generated from $\mathrm{CP}$ should be used to reduce public transport fares and make frequency and reliability improvements. They also found that car users and walkers/cyclists rated frequency improvements higher than reliability improvements, while public transport users rated reliability improvements even higher.

\section{SWOT analysis}

The analysis of CP and PC is preceded with a SWOT analysis. SWOT analysis is a structured planning method that helps evaluate the strengths, weaknesses, opportunities and threats of each pricing model, as follows:

Strengths: characteristics (relative) of the pricing model that give it an advantage over other alternatives

Weaknesses: characteristics (relative) of the pricing model that represent disadvantage relative to other alternatives

Opportunities: characteristics (absolute) of the pricing model that could be used to its advantage during implementation

Threats: characteristics (absolute) of the pricing model that could a cause of issues during implementation 
The SWOT analysis also helps the decision-makers to better understand pricing models and their effect on users and congestion in city. Results of SWOT analysis conducted are represented in Table 1.

Table 1. SWOT analysis of Park charging and Congestion pricing

\begin{tabular}{|c|c|c|}
\hline & Parking charge & Congestion pricing \\
\hline Strengths & $\begin{array}{l}\text { Reduction of car traffic } \\
\text { Reduction of parking } \\
\text { congestion } \\
\text { Generation of revenues } \\
\text { (which can be allocated to } \\
\text { Public transport subsidies } \\
\text { and infrastructure } \\
\text { investment) } \\
\text { Air quality improvement } \\
\text { Reduction of accidents } \\
\text { Reduction of Noise } \\
\text { Reduction of Climate } \\
\text { change } \\
\text { Urban space improvement } \\
\text { Better Land-use } \\
\text { Influence on long-term } \\
\text { parking users' to avoid } \\
\text { parking in the city centre }\end{array}$ & $\begin{array}{l}\text { Reduction of through car } \\
\text { traffic } \\
\text { Generation of revenues } \\
\text { (which can be allocated to } \\
\text { Public transport subsidies } \\
\text { and traffic infrastructure } \\
\text { investment) } \\
\text { Air quality improvement } \\
\text { Reduction of accidents } \\
\text { Reduction of Noise } \\
\text { Reduction of Climate } \\
\text { change } \\
\text { CP revenue can be } \\
\text { allocated to Public transport } \\
\text { subsidies and traffic } \\
\text { infrastructure investment } \\
\text { Influence on car users' } \\
\text { behaviour to avoid city } \\
\text { centre }\end{array}$ \\
\hline Weaknesses & $\begin{array}{l}\text { Parking spill-over } \\
\text { Possible negative economic } \\
\text { impacts in some sectors }\end{array}$ & $\begin{array}{l}\text { Increased traffic flows on } \\
\text { external road network } \\
\text { Possible negative economic } \\
\text { impacts in some economy } \\
\text { sectors in city central zone }\end{array}$ \\
\hline Opportunities & $\begin{array}{l}\text { Can reduce number of long- } \\
\text { term parkers } \\
\text { Dynamic pricing } \\
\text { Exemptions for some user } \\
\text { categories and residents } \\
\text { Improvement of public } \\
\text { transport } \\
\text { Investments in eco mobility }\end{array}$ & $\begin{array}{l}\text { Can tackle with through } \\
\text { traffic in congested zone } \\
\text { Can reduce short time car } \\
\text { visitors to congested zone } \\
\text { Dynamic pricing } \\
\text { Exemptions for some user } \\
\text { categories and charged } \\
\text { zone citizens categories } \\
\text { residents } \\
\text { Improvement of public } \\
\text { transport } \\
\text { Investments in eco mobility }\end{array}$ \\
\hline Threats & $\begin{array}{l}\text { Political and public } \\
\text { acceptance } \\
\text { Legislative framework } \\
\text { Social equity } \\
\text { Enforcement measures }\end{array}$ & $\begin{array}{l}\text { Political and public } \\
\text { acceptance } \\
\text { Legislative framework } \\
\text { Social equity }\end{array}$ \\
\hline
\end{tabular}

Source: Authors.

\section{Conclusion}

According to SWOT analysis one can see that both PC and $\mathrm{CP}$ policies have many similarities, hence their selection can be confusing for decision makers. However, PC and CP differ in demand segments they affect (the most), as well as in the intensity of influence. For example, while both policies reduce traffic congestion, $\mathrm{CP}$ achieve that reduction primarily by affecting through traffic and $P C$ by affecting $O D$ trips thus reducing the parking congestion as well.

Therefore, to properly select the policy, one need to think of the problem that need to be addressed: either barely traffic congestion or parking congestion as well. Further, the cause of problem need to be identified, as well as user response to policy introduction or price increase.

All the above leads to the conclusion that the policy selection and price definition must be result of comprehensive analysis. Such conclusion is also supported by current experience and findings (Section 2) which show that user response greatly depends on local circumstances and therefore results cannot be copied from another city but thoroughly investigated for each case. This leads to recommendation of this paper, that all findings from SWOT analysis need to be statistically investigated and justified in future researches.

After the selection of appropriate policy, attention should be paid to possible obstacles for its implementation. This primarily refers to winning political and public support. Wining the audience is crucial for both policies. Acceptance can be increased by education and proper communication with all stakeholders, which should create a positive image and raise awareness that TDM is necessary as a concept for managing quality of life in cities. Both policies can be successfully implemented in cases when audience understand all benefits for them and for society 


\section{References}

[1] Albert G., Mahalel D. (2006), Congestion tolls and parking fees: A comparison of the potential effect on travel behavior, Transport Policy, Vol. 13, pp.496-502

[2] Eliasson, J. (2016) 'Is congestion pricing fair? Consumer and citizen perspectives on equity effects', Transport Policy, 52, pp.1-15.

[3] Farrell, S. and Saleh, W. (2005) 'Road-user charging and the modelling of revenue allocation', Transport Policy, 12(5), pp.431-442.

[4] Glavić, D., Milenković, M., Trpković, A., Vidas, M., and Mladenović, M.N. (2017). Assessing sustainability of road tolling technologies. In Proceedings of the International Congress on Transport Infrastructure AND Systems-TIS Roma, 803 (Vol. 810).

[5] Glavić, D., Mladenović, M., Luttinen, T., Čičević, S. and Trifunović, A. (2017) 'Road to price: User perspectives on road pricing in transition country', Transportation Research Part A: Policy and Practice, 105, pp.79-94.

[6] Grisolía, J.M., López, F. and de Dios Ortúzar, J. (2015) 'Increasing the acceptability of a congestion charging scheme', Transport Policy, 39, pp.37-47.

[7] Hess S. (2001), Effect of free parking on commuter mode choice: Evidence from travel diary data, Transportation Research Record, Vol. 1753, pp.35-42

[8] Hess, S. and Börjesson, M. (2017) 'Understanding attitudes towards congestion pricing: a latent variable investigation with data from four cities', Transportation Letters, pp.1-15.

[9] Jaensirisak, S., Wardman, M. and May, A.D. (2005) 'Explaining variations in public acceptability of road pricing schemes', Journal of Transport Economics and Policy, 39(2), pp.127-154.

[10] Kelly J. A., Clinch J. P. (2006), Influence of varried parking tariffs on parking occupancy levels by trip purpose, Transport Policy, Vol. 16, pp.487-495

[11] Khodaii A., Aflaki E., Moradkhani A. (2010), Modeling the effect of parking fare on personal car use, Transaction A: Civil Engineering, Vol. 17, No. 3, pp.209- 216

[12] Litman, T., 2010. Parking Management: Strategies, Evaluation and Planning. Victoria Transport Policy Institute.

[13] Liu, C. and Zheng, Z. (2013) 'Public acceptance towards congestion charge: a case study of Brisbane', Procedia-Social and Behavioral Sciences, 96, pp.2811-2822.

[14] Marsden G. (2006), The evidence base for parking policies - a review, Transport Policy 13, pp.447-457

[15] Milenković, M., Glavić, D. and Kocic A. (2018). Analysis of users' attitudes on the introduction of congestion pricing in Belgrade. 2th International Conference „Transport for Today's Society", Bitola, Republic of North Macedonia, 17-19 May 2018.

[16] Milenković, M., Glavić, D. and Mladenović, M.N. (2018) 'Decision-Support Framework for Selecting the Optimal Road
Toll Collection System', Journal of Advanced Transportation, 2018.

[17] Nilsson, A., Schuitema, G., Bergstad, C.J., Martinsson, J. and Thorson, M. (2016) 'The road to acceptance: Attitude change before and after the implementation of a congestion tax', Journal of Environmental Psychology, 46, pp.1-9.

[18] Pierce,G.,Shoup,D.C.,2013.Gettingthepricesright.J.Am.Plan.A ssoc.79,67-81.

[19] Polk, M. 2003. "Are women potentially more accommodating than men to a sustainable transportation system in Sweden?". Transportation Research Part D 8: 75-95.

[20] Polk, M. 2004. "The influence of gender on daily car use and on willingness to reduce car use in Sweden". Journal of Transportation Geography 12: 185-195.

[21] Saleh W., Sammer G. (2009), Travel demand management and road user pricing: success, failure and feasibility, Ashgate publishing Group

[22] Schade, J. and Schlag, B. (2003) 'Acceptability of urban transport pricing strategies', Transportation Research Part F: Traffic Psychology and Behaviour, 6(1), pp.45-61.

[23] Shiftan Y., Burd-Eden R. (2001), Modeling the response to parking policy, Transportation Research Record, Vol. 1765, pp.27-34, Transportation Research Board, Washington, USA

[24] Shiftan Y., Golani A. (2005), Effect of auto restraint policies on travel behavior, Transportation Research Record: Journal of the Transportation Research Board, Vol. 1932, Transportation Research Board of the National Academies, Washington, pp.156-163

[25] Simićević, J., Milosavljević, N.: User response to parking policy change: A comparison of stated and revealed preference data, Transport Policy, vol. 46, pp. 40-45, 2016 (IF2016=3,025) (ISSN 0967-070X)

[26] Simićević, J., Momčilović, V., Milosavljević, N.: "Parking management as a means of decreasing air pollution in cities", Transport Research Arena (TRA) conference, vol. 6, no. 1, Austrija, 16-19. april 2018

[27] Simicevic, J., Vukanovic, S., \&Milosavljevic, N. (2013). The effect of parking charges and time limit to car usage and parking behaviour. Transport Policy, 30, 125-131.

[28] Transit Cooperative Research Program (TCRP) (2005), Traveler Response to Transportation System Changes, Chapter 13 - Parking Pricing and Fees, Washington DC: Transportation Research Board

[29] Van der Waerden P., Borgers A., Timmermans H. (2006), Attitudes and behavioural responses to parking measures, EJTIR, Vol. 6, No. 4, pp.301-312

[30] Verhoef E., Nijkamp P., Rietveld P. (1995), The economics of regulatory parking policies: the (im)possibilities of parking policies in traffic regulation, Transportation Research Part A, vol. 29, No. 2, pp.141-156 